\title{
Appropriate cesarean rates using Robson's Ten-Group Classification System in a Brazilian private practice
}

\author{
Andrea Silveira de Queiroz Campos ( $\square$ asqcampos@usp.br) \\ Faculdade de Saúde Pública da Universidade de São Paulo

\section{Daphne Rattner} \\ Universidade de Brasília \\ Carmen Simone Grilo Diniz \\ Faculdade de Saúde Pública da Universidade de São Paulo
}

\section{Research Article}

Keywords: Cesarean section, Supplementary Health, Health Care Models, Patient-Centered Care, Patient Care Team, Comparative evaluation in health care, Evidence-Based Practice, Humanization of Assistance, Humanized Childbirth, Maternal and Child Health

Posted Date: December 3rd, 2021

DOI: https://doi.org/10.21203/rs.3.rs-1106843/v2

License: (c) (i) This work is licensed under a Creative Commons Attribution 4.0 International License. Read Full License 


\section{Abstract \\ Background}

The increasing rates of cesarean sections (CS) in places with adequate access to health care are a global concern because they are related to higher rates of maternal and neonatal complications and do not provide a positive childbirth experience for women. The objective is to highlight the possibility of achieving CS rates acceptable by WHO standards, such as Nordic countries, following evidence-based protocols in Brazil.

\section{Methods}

A cross-sectional study evaluated CS rates by Robson Groups for women who sought vaginal delivery in a private health practice in Brazil, comparing the rates with Swedish data. A collaborative practice with midwives and obstetricians adopting evidence-based guidelines was offered. The overall CS rate, CS rate by Robson group, contribution of each Robson group to the overall CS rate, clinical and nonclinical interventions and vaginal birth, pre-labour CS and intrapartum CS proportions were estimated. The expected CS rate for the population was calculated by the WHO c-model tool. The analysis used Microsoft EXCEL and the software "R Studio" (version 1.2.1335. 2009-2019).

\section{Results}

The overall CS rate was $15.1 \%$ (as expected by the WHO c-model tool) in a population composed of $43.7 \%$ women in Robson Group 1 , $11.4 \%$ in Group 2 and $14.9 \%$ in Group 5, the greatest responsible for higher rates of CS, who altogether contributed to $75.4 \%$ of all cesarean sections.

\section{Conclusions}

Multidisciplinary care following evidence-based protocols, associated with a high motivation of both women and professionals of childbirth care for a vaginal route for delivery, may lead to a significant and safe reduction of CS rates, obtaining better results even in contexts such as Brazil, where there is high medicalization of obstetric care and excess of CS.

\section{Background}

Cesarean section (CS) is a life-saving obstetric intervention for women and newborns when there are complications in childbirth, but when performed without medical reasons, it may be related to short- and long-term complications. CSs without clinical indication have grown globally, having exceptionally high levels in large urban centers' private sector, motivating the World Health Organization (WHO) and government agencies to create strategies for their control. ${ }^{1,2}$

The proportion of births by CS per health service is a helpful indicator of quality in obstetric care, and its audit is essential to understand trends and associated factors. Variations in the overall rate of CSs are challenging to interpret due to heterogeneity in the infrastructure of health services, obstetric population and protocols used and to facilitate evaluation, comparison and implementation of improvements, WHO proposed using the Robson Classification, which is fully inclusive and mutually exclusive and classifies women into homogeneous groups, well-defined and clinically relevant, based on obstetric variables at the time of hospital admission for delivery. ${ }^{3,4}$

In 2019, Brazil ranked second in the world, with an overall cesarean rate of 57\%, and the supplementary sector (health insurance) was responsible for financing 287166 of the 2849146 deliveries, which corresponds to $10 \%$ of the births. In this sector, the proportion of births by CS was $85 \%$ that year. ${ }^{5}$

São Paulo is its most populous city, with a Human Development Index of 0.805 (very high. according to United Nations standards in 2000) and is in stage IV of the obstetric transition (low fertility and maternal mortality rate, mainly due to indirect causes, being the strategy recommended for this stage to improve the qualification in care and the reduction of excess interventions in childbirth) and one of the cities with the highest health insurance health coverage in Brazil $(43 \%, 95 \% \mathrm{Cl} 40 \%-47 \%),{ }^{6,7}$

Appropriate interventions in childbirth, classified as clinical and nonclinical, can avoid the need for CS, but clinical interventions can be harmful when overused. 8,9 
Clinical interventions guided by evidence-based protocols aim at individualized obstetric practice and slightly impact the rate of CSs because the proportion of CSs without clinical reasons is high in countries with high rates of this procedure, such as Brazil. Examples include external cephalic version in cases of full-term breech presentation, vaginal breech delivery for selected cases, vaginal delivery after CS, neuraxial analgesia and labour induction in selected cases. ${ }^{8}$

Nonclinical interventions tend to have a more significant impact on the reduction of CS rates because they influence the reduction of procedures without obstetric indication and include measures such as education for childbirth, continuous support in labour (provided by a companion of choice of the woman and by the presence of a doula) and care provided by midwives. Such interventions increase the rate of physiological deliveries and lower rates of complications, in addition to providing a positive experience of childbirth to women. ${ }^{10}$

CS rates may vary according to the complexity of the facility, epidemiological characteristics of the population attended and the care protocols used. ${ }^{2}$ For this reason, a tool called c-model was developed to estimate the expected CS rate considering maternal age, obstetric characteristics used for Robson's classification and the incidence of comorbidities in the population, such as placenta previa, abruptio placentae, chronic hypertension, pre-eclampsia, kidney disease, HIV and organic dysfunction with intensive care unit (ICU) admission. 2,11

Nordic countries (Denmark, Finland, Iceland, Norway, and Sweden) have maintained lower CS rates (approximately 17\%) combined with good perinatal outcomes, and the region is considered a world reference for good obstetric practices; for this reason, Swedish data may be adopted as a gold standard. In these countries, childbirth care is less medicalized than in most developed countries, midwives care for habitual risk births, and obstetricians are called only when problems arise. ${ }^{2,12}$

The present study presents CS rates by Robson's groups in a population of women seeking a vaginal delivery and a positive experience of childbirth and compares them with data from Sweden, demonstrating the possibility of obtaining CS rates acceptable by WHO standards in Brazil, such as those of Nordic countries, by following evidence-based protocols and offering care and follow-up by a multidisciplinary team.

\section{Methods}

This study adopted a cross-sectional design to evaluate CS rates by Robson Groups in women of a private practice (PP) of São Paulo city, assisted from 2004 to 2019.

The inclusion criteria were women who sought prenatal care and childbirth with the intention of a spontaneous vaginal delivery with appropriate use of technology, with single or multiple pregnancies, who gave birth in a hospital to a newborn or stillborn, with birth weight greater than or equal to 500 grams and/or gestational age greater than or equal to 22 weeks of gestation. Women with planned home birth were excluded.

All women were followed by a multidisciplinary team led by an obstetrician since the antenatal period. During the visits, clinical and nonclinical aspects of childbirth care and perinatal education and promotion of vaginal birth as a positive experience were broached, respecting the woman's autonomy. An obstetrician was present in all births (including low risk) and prioritized the active phase for childbirth admission. When a midwife was part of the team, there were alternate antenatal visits by her and the obstetrician, and she did the first evaluation of the birth process at the woman's home, the obstetrician coming to the birth from dilation at $6 \mathrm{~cm}$ on, or before if there were complications or the woman asked for analgesia.

In labour, they had continuous support, the presence of a companion and/or a doula of their choice; completion of delivery registered in their medical record; use of non-pharmacological methods for pain relief; freedom of movement during labour; free food ingestion; freedom of choice of position for delivery and no use of a peripheral venous catheter, oxytocin or routine amniotomy. ${ }^{13}$

The primary outcome assessed was the overall CS rate, sizes of the Robson groups of women, CS rate in each group and contribution to the overall CS rate from each groupand the results were discussed. The secondary ones were the frequency of some clinical and nonclinical interventions in childbirth and sociodemographic characteristics (analyzed by a binary logistic regression model); the rate of vaginal birth, pre-labour CS and intrapartum CS; and the expected CS rate for the population by the WHO c-model tool.

The databases' construction and manipulation and tables and figures elaboration were carried out using Microsoft Excell and the software "R Studio" (version 1.2.1335. 2009-2019) ${ }^{14}$.

The database and R-scripts were shared at the Figshare open access repository and are available at https://doi.org/10.6084/m9.figshare.17057777.v1. 
The study received ethical approval from the Research Ethics Committee of the Faculdade de Saúde Pública da Universidade de São Paulo through national Plataforma Brasil under the Certificate of Presentation of Ethical Appreciation (CAAE) number 50733621.8.0000.5421 on September 16, 2021, based on the Helsinki declaration. The ethical committee approved that individual informed consent was not considered due to the confidential handling of the data presented without identifying the individuals.

\section{Robson's Ten-Group Classification System}

Robson's ten groups classify women according to six obstetric variables at hospital admission for delivery: the number of fetuses (single or multiple pregnancies); fetal presentation (cephalic, breech and transverse); parity (nulliparous or multiparous); gestational age (preterm or term); presence (or absence) of previous CS; and onset of labour (spontaneous, induced and pre-labour CS). (see Figure 1)

\section{Results}

From 2004 to 2019, 1481 women who came from support groups for pregnant women and internet search tools sought this PP care and were followed up. Their sociodemographic and obstetric characteristics are described in Table 1. 
Table 1

Distribution of women, CS and CS rates according to maternal characteristics in a private practice. Brazil, 2004-2019

\begin{tabular}{|c|c|c|c|c|c|}
\hline & \multicolumn{2}{|c|}{ Women } & \multicolumn{2}{|l|}{ CS } & \multirow{2}{*}{$\begin{array}{l}\text { CS rate } \\
\%\end{array}$} \\
\hline & No. & $\%$ & No. & $\%$ & \\
\hline \multicolumn{6}{|l|}{ Maternal age in years } \\
\hline$<20$ & 1 & 0.1 & 0 & 0.0 & 0.0 \\
\hline $20-34$ & 1087 & 73.4 & 152 & 67.9 & 14.0 \\
\hline$>34$ & 387 & 26.1 & 69 & 30.8 & 17.8 \\
\hline Ignored & 6 & 0.4 & 3 & 1.3 & 50.0 \\
\hline \multicolumn{6}{|l|}{ Race/color ${ }^{1}$} \\
\hline White & 1333 & 90.0 & 194 & 86.6 & 14.6 \\
\hline Non-white & 87 & 5.9 & 15 & 6.7 & 17.2 \\
\hline Ignored & 61 & 4.1 & 15 & 6.7 & 24.6 \\
\hline \multicolumn{6}{|c|}{ Marital status (stable union) } \\
\hline With & 1241 & 83.8 & 184 & 82.1 & 14.8 \\
\hline Without & 224 & 15.1 & 36 & 16.1 & 16.1 \\
\hline Ignored & 16 & 1.1 & 4 & 1.8 & 25.0 \\
\hline \multicolumn{6}{|c|}{ Education (tertiary education) } \\
\hline With & 1344 & 90.7 & 201 & 89.7 & 15.0 \\
\hline Without & 61 & 4.1 & 5 & 2.2 & 8.2 \\
\hline Ignored & 76 & 5.1 & 18 & 8.0 & 23.7 \\
\hline \multicolumn{6}{|c|}{ Obstetric characteristics (Robson Group) } \\
\hline 1 and 2 & 815 & 55.0 & 124 & 55.4 & 15.2 \\
\hline 3 and 4 & 314 & 21.2 & 2 & 0.9 & 0.6 \\
\hline 5 & 220 & 14.9 & 45 & 20.1 & 20.5 \\
\hline 6,7 and 9 & 41 & 2.8 & 29 & 12.9 & 70.7 \\
\hline 8 & 19 & 1.3 & 9 & 4.0 & 47.4 \\
\hline 10 & 72 & 4.9 & 15 & 6.7 & 20.8 \\
\hline High risk pregnancy ${ }^{2}$ & 120 & 8.1 & 36 & 16.1 & 30.0 \\
\hline \multicolumn{6}{|c|}{ Provider-initiated chidbirth } \\
\hline Spontaneous labor ${ }^{3}$ & 1163 & 78.5 & 115 & 51.3 & 9.9 \\
\hline Induced 4 & 264 & 17.8 & 55 & 24.6 & 20.8 \\
\hline Pre-labour CS & 54 & 3.6 & 54 & 24.1 & 100.0 \\
\hline \multicolumn{6}{|l|}{ Intrapartum care } \\
\hline Presence of Doula & 928 & 62.7 & 132 & 58.9 & 14.2 \\
\hline Presence of Midwife & 1090 & 73.6 & 133 & 59.4 & 12.2 \\
\hline Analgesia $^{5}$ & 623 & 42.1 & 170 & 75.9 & 27.3 \\
\hline Notes: & & & & & \\
\hline
\end{tabular}




\begin{tabular}{|lccccc|}
\hline & Women & CS & & CS rate \\
\hline Total & 1481 & 100.0 & 224 & 100.0 & 15.1 \\
\hline Notes: & & & & & \\
\hline
\end{tabular}

1: according to provider

2: placenta previa, abruptio placentae, chronic hypertension, preeclampsia, kidney disease, HIV and organ dysfunction with ICU admission.

3: on arrival, 3 contractions per 10 min with cervical effacement $>50 \%$ and dilation $>3 \mathrm{~cm}$ with intact or ruptured membranes.

4: use of misoprostol, Foley catheter or oxytocin in a woman who does not fulfill the criteria for spontaneous labor

5: Pre-labour CS not included

Source: PP data

For a more synthetic presentation, Robson groups were grouped according to their obstetric characteristics: groups 1 and 2, representing the nulliparous term singleton vertex (NTSV); 3 and 4 representing the multiparous term singleton vertex with no CS (MTSVnoCS); and 6, 7 and 9 representing noncephalic presentation (NCP).

Most women were between 20 and 34 years old, white race/color, with a stable union and with tertiary education. Considering the obstetrics characteristics, the largest group was of NTSV, followed by MTSVnoCS, and by multiparous term singleton vertex with CS. These three groups, altogether, were responsible for $91.1 \%$ of the population and for $76.4 \%$ of the CS.

A doula and/or a midwife were present in most cases, and during labour and delivery, women were encouraged to move around and use nonpharmacological methods for pain relief and free choice of position for delivery. Labour analgesia was performed at women's request and occurred in 623 births (42.1\%).

The statistical analysis of the sociodemographic characteristics and clinical and nonclinical interventions described in Table 1 showed no influence on the probability of a CS in the binary logistic regression model while keeping the other variables constant.

The distribution of vaginal birth, pre-labour CS and intrapartum CS according to obstetrics characteristics is displayed in Table 2, which shows a very low proportion of pre-labour CS, with these more frequent in the NCP group.

Table 2

- Distribution of vaginal birth, pre-labour and intrapartum cesarean sections of a private practice by Robson Groups. Brazil, 2014-2019

\begin{tabular}{|lllllllll|}
\hline & \multicolumn{2}{l}{ Women } & \multicolumn{7}{c}{ Vaginal birth } & \multicolumn{2}{c|}{ Pre-labour CS } & \multicolumn{2}{c|}{ Intrapartum CS } \\
\hline Robson Groups & $\mathbf{N}$ & $\%$ & $\mathbf{N}$ & $\%$ & $\mathbf{N}$ & $\%$ & $\mathbf{N}$ & $\%$ \\
\hline $1+2$ & 815 & 55.0 & 691 & 84.8 & 10 & 1.2 & 114 & 14.0 \\
\hline $3+4$ & 314 & 21.2 & 312 & 99.4 & 0 & 0.0 & 2 & 0.6 \\
\hline 5 & 220 & 14.9 & 175 & 79.5 & 9 & 4.1 & 36 & 16.4 \\
\hline $6+7+9$ & 41 & 2.8 & 12 & 29.3 & 25 & 61.0 & 4 & 9.8 \\
\hline 8 & 19 & 1.3 & 10 & 52.6 & 2 & 10.5 & 7 & 36.8 \\
\hline 10 & 72 & 4.9 & 57 & 79.2 & 8 & 11.1 & 7 & 9.7 \\
\hline Total & 1481 & $\mathbf{1 0 0 . 0}$ & $\mathbf{1 2 5 7}$ & $\mathbf{8 4 . 9}$ & $\mathbf{5 4}$ & $\mathbf{3 . 6}$ & $\mathbf{1 7 0}$ & $\mathbf{1 1 . 5}$ \\
\hline Source: PP data. & & & & & & & & \\
\hline
\end{tabular}


Table 3 presents a Robson report table of the PP and of Sweden (S), obtained at Svensk Förening För Obstetrik Och Gynekologi (SFOG), as proposed by the WHO publication. ${ }^{2,15}$ 
Table 3

Robson report table for a private practice (Brazil, 2014 to 2019) (PP) and Sweden (2019) (S).

\begin{tabular}{|c|c|c|c|c|c|c|c|c|c|c|c|c|}
\hline \multirow[t]{2}{*}{ Group } & \multicolumn{2}{|c|}{$\begin{array}{l}\text { NCS in } \\
\text { group }\end{array}$} & \multicolumn{2}{|c|}{ Total $\mathbf{N}$ in group } & \multicolumn{2}{|c|}{$\begin{array}{l}\text { Group } \\
\text { size (\%) }\end{array}$} & \multicolumn{2}{|c|}{$\begin{array}{l}\text { Group CS } \\
\text { rate }(\%)^{2}\end{array}$} & \multicolumn{2}{|c|}{$\begin{array}{l}\text { Absolute group } \\
\text { contribution to overall CS } \\
\text { rate }(\%)^{3}\end{array}$} & \multicolumn{2}{|c|}{$\begin{array}{l}\text { Relative group } \\
\text { contribution to overall CS } \\
\text { rate }(\%)^{4}\end{array}$} \\
\hline & PP & $s$ & PP & $s$ & PP & $s$ & PP & $s$ & PP & $s$ & PP & $s$ \\
\hline 1 & 78 & 2259 & 647 & 30356 & $\begin{array}{l}43 . \\
7\end{array}$ & $\begin{array}{l}27 . \\
0\end{array}$ & $\begin{array}{l}12 . \\
1\end{array}$ & 7.4 & 5.3 & 2. 0 & 34.8 & 11. 3 \\
\hline 2 & 46 & 4053 & 168 & 12075 & $\begin{array}{l}11 . \\
4\end{array}$ & $\begin{array}{l}10 . \\
7\end{array}$ & $\begin{array}{l}27 . \\
4\end{array}$ & $\begin{array}{l}33 . \\
6\end{array}$ & 3.1 & 3.6 & 20.5 & 20.2 \\
\hline $\begin{array}{l}2 \mathrm{a} \\
\text { (induced) }\end{array}$ & 36 & 2422 & 158 & 10444 & $\begin{array}{l}10 . \\
7\end{array}$ & $\begin{array}{l}9 . \\
3\end{array}$ & $\begin{array}{l}22 . \\
8\end{array}$ & $\begin{array}{l}23 . \\
2\end{array}$ & 2. 4 & 2. 2 & 16. 1 & 12. 1 \\
\hline $\begin{array}{l}\text { 2b (Pre- } \\
\text { labour CS) }\end{array}$ & 10 & 1631 & 10 & 1631 & 0. & $\begin{array}{l}1 . \\
5\end{array}$ & $\begin{array}{l}100 . \\
0\end{array}$ & $\begin{array}{l}100 . \\
0\end{array}$ & 0.7 & 1.5 & 4. 5 & 8. 1 \\
\hline 3 & 1 & 577 & 272 & 37718 & $\begin{array}{l}18 . \\
4\end{array}$ & $\begin{array}{l}33 . \\
6\end{array}$ & 0.4 & 1.5 & 0.1 & 0.5 & 0.5 & 2. 9 \\
\hline 4 & 1 & 1799 & 42 & 10760 & $\begin{array}{l}2 . \\
8\end{array}$ & $\begin{array}{l}9 . \\
6\end{array}$ & 2. 4 & $\frac{16 .}{7}$ & 0.1 & 1.6 & 0.5 & 9.0 \\
\hline $\begin{array}{l}4 a \\
\text { (Induced) }\end{array}$ & 1 & 399 & 42 & 9360 & $\begin{array}{l}2 . \\
8\end{array}$ & $\begin{array}{l}8 . \\
3\end{array}$ & 2. 4 & 4. 3 & 0.1 & 0.4 & 0.5 & 2. 0 \\
\hline $\begin{array}{l}\text { 4b (Pre- } \\
\text { labour CS) }\end{array}$ & 0 & 1400 & - & 1400 & - & 1. & - & $\begin{array}{l}100 . \\
0\end{array}$ & - & 1.2 & - & 7. 0 \\
\hline 5 & 45 & 5680 & 220 & 10375 & $\begin{array}{l}14 . \\
9\end{array}$ & $\begin{array}{l}9 . \\
2\end{array}$ & $\begin{array}{l}20 . \\
5\end{array}$ & $\begin{array}{l}54 . \\
7\end{array}$ & 3. 0 & 5. 1 & 20.1 & 28. 3 \\
\hline 5.1 (1 CS) & 39 & - & 201 & - & $\begin{array}{l}13 . \\
6\end{array}$ & - & $\begin{array}{l}19 . \\
4\end{array}$ & - & 2.6 & - & 17.4 & - \\
\hline $5.2(>1 \mathrm{CS})$ & 6 & - & 19 & - & $\begin{array}{l}1 . \\
3\end{array}$ & - & $\begin{array}{l}31 . \\
6\end{array}$ & - & 0.4 & - & 2. 7 & - \\
\hline 6 & 25 & 1794 & 33 & 1940 & 2. & 7. & $\begin{array}{l}75 . \\
8\end{array}$ & $\begin{array}{l}92 . \\
5\end{array}$ & 1.7 & 1.6 & 11.2 & 8. 9 \\
\hline 7 & 4 & 1024 & 8 & 1176 & $\begin{array}{l}0 . \\
5\end{array}$ & $\begin{array}{l}1 . \\
0\end{array}$ & $\begin{array}{l}50 . \\
0\end{array}$ & $\begin{array}{l}87 . \\
1\end{array}$ & 0.3 & 0.9 & 1. 8 & 5.1 \\
\hline 8 & 9 & 908 & 19 & 1640 & $\begin{array}{l}1 . \\
3\end{array}$ & $\begin{array}{l}1 . \\
5\end{array}$ & $\begin{array}{l}47 . \\
4\end{array}$ & $\begin{array}{l}55 . \\
4\end{array}$ & 0.6 & 0.8 & 4. 0 & 4. 5 \\
\hline 9 & 0 & 355 & - & 375 & - & $\begin{array}{l}0 . \\
3\end{array}$ & - & $\begin{array}{l}94 . \\
7\end{array}$ & - & 0.3 & - & 1.8 \\
\hline 10 & 15 & 1616 & 72 & 4903 & $\begin{array}{l}4 . \\
9\end{array}$ & $\begin{array}{l}4 . \\
4\end{array}$ & $\begin{array}{l}20 . \\
8\end{array}$ & $\begin{array}{l}33 . \\
0\end{array}$ & 1. 0 & 1.4 & 6.7 & 8. 1 \\
\hline Total & 224 & 20065 & 1481 & 112339 & $100 . c$ & & $\begin{array}{l}15 . \\
1\end{array}$ & $\begin{array}{l}17 . \\
9\end{array}$ & 15.1 & 17.9 & 100.0 & \\
\hline
\end{tabular}




\begin{tabular}{|c|c|c|c|c|c|c|}
\hline Group & $\begin{array}{l}\text { NCS in } \\
\text { group }\end{array}$ & Total $\mathbf{N}$ in group & $\begin{array}{l}\text { Group } \\
\text { size }(\%)^{1}\end{array}$ & $\begin{array}{l}\text { Group CS } \\
\text { rate }(\%)^{2}\end{array}$ & $\begin{array}{l}\text { Absolute group } \\
\text { contribution to overall CS } \\
\text { rate }(\%)^{3}\end{array}$ & $\begin{array}{l}\text { Relative group } \\
\text { contribution to overall CS } \\
\text { rate }(\%)^{4}\end{array}$ \\
\hline
\end{tabular}

1. $\%=\mathrm{n}$ of women in the group / total $\mathrm{N}$ women delivered in the setting $\mathrm{x} 100$

2. $\%=\mathrm{n}$ of $\mathrm{CS}$ in the group / total $\mathrm{N}$ of women in the group $\times 100$

3. $\%=\mathrm{n}$ of $\mathrm{CS}$ in the group / total $\mathrm{N}$ of women delivered in the setting $\times 100$

4. $\%=n$ of CS in the group / total $\mathrm{N}$ of CS in the setting $\times 100$

Definitions used in this setting:

Spontaneous labour. on arrival 3 contractions / 10 min with cervical effacement $>50 \%$ and dilation $>3 \mathrm{~cm}$, with intact or ruptured membranes.

Induction: use of misoprostol, Foley catheter or oxytocin in a woman who does not fulfill the criteria for spontaneous labour.

Source: PP data, SFOG ${ }^{15}$

Figure 2 displays the size and CS rates of the Robson groups grouped by common characteristics for the PP and Sweden. In the PP, the nulliparous group was larger and the multiparous group was smaller, with a greater proportion of women with a previous CS.

For both the PP and Sweden, groups 1,2 and 5 were the ones that contributed most to the general CS rate of the studied population (relative group contribution to overall CS rate), with the CS rates being lower for the PP in groups 2 and 5 .

The submission of the PP database to the WHO c-model tool generated an expected CS rate for this population of $20.7 \%(95 \% \mathrm{Cl} 15.6 \%$ $26.0 \%)$, with no statistically significant difference taking into account the $95 \%$ confidence interval of the observed rate of $15.1 \%(\mathrm{Cl} 13.3 \%$ $17.1 \%){ }^{16}$

\section{Discussion}

The CS rate found in the PP was similar to that estimated by the c-model tool, as well as to a database with low CS rates and good perinatal outcomes, such as Sweden ${ }^{17}$. For countries with high CS rates, such as Brazil, differences between rates observed and estimated by the c-model are usually higher. ${ }^{16,18-20}$ The groups that most contributed to a lower rate in the PP were groups 2 (particularly group 2a) and 5, a result that also differs from the rates found in the WHO Global Survey of Maternal and Perinatal Health study. ${ }^{21}$

Women of the PP population had predominantly a single child, with a low natality rate, since they presented a proportion of NTSV greater than the expected by the WHO; this group had low rates of induction of birth and pre-labour CS, reinforcing that such interventions were performed only for medical reasons. ${ }^{2,22}$

Group 5 contributed to $14.9 \%$ of the population, and its size is related to the general population CS rate. The important size of group 5 reflects a longer-than-expected history of CSs, as it is represented by women nulliparous in their previous pregnancy who underwent a CS. In places with low cesarean rates, it usually contributes to less than $10 \%$ of women ${ }^{2}$.

The CS rates of this PP were lower than those of other Brazilian studies published for all Robson groups, considering both the public and private sectors, including teaching hospitals, that should adopt the evidence-based protocols of the Brazilian Ministry of Health. ${ }^{23-26}$ Studies that evaluated the quality of obstetric care practiced in the country evinced an excessively interventionist practice, e.g., absence of evidence-based protocol use, with intervention rates even higher in high-income locations, with no improvement in the quality of maternity services and with increases in both the risk of iatrogenic harm and costs. ${ }^{27-30}$

According to the WHO, half of all CSs occur in group 5; PP Group 5 displayed a CS rate of $20.5 \%$, representing $20 \%$ of all CSs performed. For Group 5, cesarean rates between 50 and $60 \%$ are expected. ${ }^{2,22}$

This rate contrasts even more when compared to a private population of cases eligible for vaginal birth after a cesarean section, which had an elective CS rate of $95.3 \%$ and $39,2 \%$ of intrapartum CS in this group, suggesting that nonclinical factors are leading to CS iteration in these services. ${ }^{23}$ 
The significantly lower rates obtained in the PP may be due to: use of evidence-based protocols; women's desire for a vaginal birth, professionals enabling all measures to facilitate it; continuous support for women during childbirth; and, for women in group 5, the willingness of both the woman and the professionals to allow a trial of labour; and the absence of obstetric indication for the previous CS, typical of populations with high cesarean rates ${ }^{31}$.

The collaborative and multidisciplinary model, involving obstetricians and midwives, is an effective and successful model for the improvement of obstetric care (including high-risk cases), reducing adverse perinatal events and increasing safety and women's satisfaction with her birth; it encourages a patient- and family-centered practice and is tuned to the WHO recommendations for a positive childbirth experience. A study that compared the prevalence of CS and neonatal outcomes in two models of childbirth care in Brazilian private hospitals showed a lower CS rate, with no difference in neonatal outcomes, with the model of care offered by the multidisciplinary team. ${ }^{30,32-35}$

This study's strengths rely on the fact that all interventions were performed for medical reasons, following evidence-based protocols and guidelines; the motivation for a vaginal birth and a positive childbirth experience, both from the women and the multidisciplinary team; and the quality of the data, a great concern of these PP professionals, supported by the fact that no woman was left out of Robson's groups classification.

Potential limitations include: its population is composed majorly of women seeking a vaginal birth and women with a higher risk for a CS or a contraindication for a vaginal birth might have been excluded; all women were from the private sector and, in this town, this represents less than half of the population; all patients were cared by a team with the same professional as a leader and, given this database was collected throughout various years, changes in the team and in the conducts were not considered, Besides, maternal and neonatal outcomes were not object of this study, as well as the evaluation of the women's experience. Another limiting factor is the low coverage of midwives given the additional fee charged by them: this might have discouraged women who had their follow-up during the antenatal care to hire them for the birth. Low coverage of such midwifery services is described as a barrier to the implementation of collaborative care in the US. ${ }^{36}$

This study results, although in a small population, demonstrate the real possibility of obtaining CS rates according to those displayed in WHO publications by offering multidisciplinary childbirth care that follows evidence-based protocols and proposes to provide a positive childbirth experience as recommended by the WHO. Health policies should promote health education to the population and health professionals, focusing on disseminating and implementing such practices both in the public and private sectors.

\section{Conclusion}

Multidisciplinary care following evidence-based protocols, associated with a high motivation of both women and professionals of childbirth care for a vaginal route for delivery, may lead to a significant and safe reduction of CS rates, obtaining better results even in contexts such as Brazil, where there is high medicalization of obstetric care and excess CS.

Such professionals' and women's motivation may be improved by government educational campaigns that would promote childbirth care towards a positive childbirth experience as recommended by the WHO, as well as by the implementation of the collaborative care model with midwives, both in the public. and the private sectors.

\section{Abbreviations}

$\mathrm{Cl}$

confidence interval

CS

caesarean section

ICU

intensive care unit

MTSVnocs

multiparous term singleton vertex whithout CS

NCP

non cephalic presentation

NTSV

nulliparous term singleton vertex 
PP

private practice

SFOG

Svensk Förening För Obstetrik Och Gynekologi

$S$

Sweden

WHO

World Healh Organization

\section{Declarations}

\section{- Ethics approval and consent to participate}

The study received ethical approval from the Research Ethics Committee of the Faculdade de Saúde Pública da Universidade de São Paulo through national Plataforma Brasil under the Certificate of Presentation of Ethical Appreciation (CAAE) number 50733621.8.0000.5421 on September 16, 2021, based on the Helsinki declaration. The ethical committee approved that individual informed consent was not considered due to the confidential handling of the data presented without identifying the individuals.

\section{- Consent for publication}

Not applicable

\section{- Availability of data and materials}

The datasets generated and/or analysed during the current study are available in the Figshare repository at https://doi.org/10.6084/m9.figshare.17057777.v1.

\section{- Competing interests}

The authors declare that they have no competing interests.

\section{- Funding}

Funded by the authors.

\section{- Authors' contributions}

ASQC, CSGD and DR were involved in the conception and study design, analysis and interpretation of data and drafting of the article. ASQC was involved with data acquisition, and DR was involved with critical revision of the article. All authors read and approved the final manuscript.

\section{- Acknowledgements}

The authors wish to thank M. A. B. Dias, M. L. S. Takemoto and P. M. M. Bermudi for their assistance in writing this paper and L. P. Fascina, manager of the maternity and pediatric units of Hospital Israelita Albert Einstein.

\section{- Authors' information}

ASQC: Master's degree student of the Programa de Saúde Pública at the Faculdade de Saúde Pública da Universidade de São Paulo within the project "Quality in Childbirth Care: Results of a Model of Care in a Private Practice of São Paulo City". Graduated in Medicine at the Universidade de Mogi das Cruzes (2001), specialized in Tocogynecology at Hospital Maternidade Leonor Mendes de Barros (2002), Pelvic Oncology and Mastology at Hospital Pérola Byington (2003). She participated in the X Basic Course on Anthroposophical Medicine from the Brazilian Association of Anthroposophical Medicine (2008) and the Women's Health course under the vision of Anthroposophical Medicine at the Universidade Federal de São Paulo (2009). In 2018, she completed a postgraduate course in Bases of Integrative Medicine at Faculdade Israelita de Ciências da Saúde Albert Einstein. Since 2001, she has been working at the municipal health secretariat of São Paulo, and since 2004, she has been providing consultations in private practice with a multidisciplinary model of humanized obstetric care, being a founding partner of Casa Moara (2010). In 2018, she created the health education portal www.meuparto.com, where she brings information to women for a positive childbirth experience. 
DR: Graduated in Medicine from the Universidade Estadual de Campinas (1976), Master's in Epidemiology from the Universidade de São Paulo (1991) and Ph.D. in Epidemiology - University of North Carolina (2001). She worked as a Specialized Technician in the Technical Area of Women's Health at the Ministry of Health from 2004 to 2009. She is currently an Associate Professor of Epidemiology at the Department of Public Health, Faculty of Health Sciences, at the University of Brasília. She has experience in the field of medicine and public health, with emphasis on women's and children's health, working mainly on the following topics: epidemiology, quality, obstetrics, public health, obstetric care and perinatal care. With the Belkis Trench, she organized the book Humanizando Nascimentos e Partos. She is president of the Rede pela Humanização do Parto e Nascimento - ReHuNa (the Brazilian Network for the Humanization fo Childbirth); is on the board of the International MotherBaby Childbirth Organization; she is Counselor of the Instituto Anchieta do Grajaú; Red por la Humanización del Childbirth y Nacimiento de América Latina y Caribe - Relacahupan; Ibfan-Brasil Network (International Breastfeeding Action Network); Associação Nacional de Doulas- ANDO. She is a member of the following Committees of the Ministry of Health as an expert: Expert Committee of Rede Cegonha (Stork Network); Rede Cegonha Social Mobilization Committee; Committee on Normal Childbirth, Center for Emergency Operations in Public Health - COES-Microcephaly. As president of ReHuNa, since 2015, he has been a member of the Advisory Committee of the international movement 'Una Promesa Renova para las Américas' (A promess renewed). Since May 2020, she has been a member of the Global Respectful Maternity Care Council.

CSGD: Graduated in Medicine from the Federal University of Rio Grande do Norte (1984). Residence (1987), master's (1996) and doctorate (2001) degrees in Medicine (Preventive Medicine), University of São Paulo, and post-doctoral program in Maternal and Child Health at Cemicamp (2004). Postdoctoral (visiting reader) at King's College London, Women's Health Division (2012). She is a full professor in the Department of Health, Life Cycles and Society at the School of Public Health, University of São Paulo (2011). She collaborated for 20 years with the Feminist Collective Sexuality and Health (1985-2004) in health care activities, research and training. She has experience in medicine, with emphasis on preventive medicine, Sexual and Reproductive Health and Rights, Gender Violence, Gender and Maternal Health, Maternal and Child Health, evidence-based Public Health. She was a regional coordinator (Southeast Region) of the Birth in Brazil National Survey (2010-2012). Coordinates the CNPq group GEMAS (Gender and evidence on maternity and health). She was head of the Department of Maternal and Child Health Public Health School of USP (2014-2017). She coordinates the Mother and Child-friendly Hospital Initiative implementation study with a FAPESP grant. She also coordinates the Potential Lost Days of Pregnancy (DPGP) project: an innovative measure of gestational age to assess maternal and child health interventions and outcomes, funded by the CNPq and the Bill and Melinda Gates Foundation.

\section{References}

1. Betrán AP, Ye J, Moller A-B, Zhang J, Gülmezoglu AM, Torloni MR. The Increasing Trend in Caesarean Section Rates: Global, Regional and National Estimates: 1990-2014. PLOS ONE 2016; 11. DOI:10.1371/journal.pone.0148343.

2. WHO - World Health Organization. Robson classification: implementation manual. 2017 https://apps.who.int/iris/handle/10665/259512 (accessed Aug 29, 2021).

3. Robson MS. Classification of caesarean sections. Fetal Matern Med Rev 2001; 12: 23-39.

4. WHO - World Health Organization, RHR - Department of Reproductive Health and Research. WHO Statement on Caesarean Section Rates. Geneva, 2015 https://apps.who.int/iris/bitstream/handle/10665/161442/WHO_RHR_15.02_eng.pdf;sequence=1 (accessed Nov 18, 2021).

5. DASNT - Departamento de Análise em Saúde e Vigilância das Doenças Não Transmissíveis. Painel de Monitoramento de Nascidos Vivos. 2021. http://svs.aids.gov.br/dantps/centrais-de-conteudos/paineis-de-monitoramento/natalidade/nascidos-vivos/.

6. CElnfo - Coordenação de Epidemiologia e Informação. Boletim ISA Capital 2015, n 19, 2019: Saúde Suplementar na cidade de São Paulo. 2019;: 38.

7. Souza J, Tunçalp Ö, Vogel J, et al. Obstetric transition: the pathway towards ending preventable maternal deaths. BJOG 2014; 121: 14.

8. Miller S, Abalos E, Chamillard M, et al. Beyond too little, too late and too much, too soon: a pathway towards evidence-based, respectful maternity care worldwide. The Lancet 2016; 388: 2176-92.

9. Betrán AP, Temmerman M, Kingdon C, et al. Interventions to reduce unnecessary caesarean sections in healthy women and babies. The Lancet 2018; 392. DOI:10.1016/S0140-6736(18)31927-5.

10. Dias MAB, Domingues RMSMR, Schilithz AOC, et al. Factors associated with cesarean delivery during labour in primiparous women assisted in the Brazilian Public Health System: data from a National Survey. Reproductive Health 2016; 13. DOI:10.1186/s12978-0160231-z. 
11. Souza J, Bétran A, Dumont A, et al. A global reference for caesarean section rates (C-Model): a multicountry cross-sectional study. BJOG 2016; 123: 427-36.

12. Pyykönen A, Gissler M, Løkkegaard E, et al. Cesarean section trends in the Nordic Countries - a comparative analysis with the Robson classification. Acta Obstetricia et Gynecologica Scandinavica 2017; 96: 607-16.

13. Bohren MA, Hofmeyr GJ, Sakala C, Fukuzawa RK, Cuthbert A. Continuous support for women during childbirth. Cochrane Database of Systematic Reviews 2017; published online July 6. DOI:10.1002/14651858.CD003766.pub6.

14. R CoreTeam. R: A language and environment for statistical computing. 2021. https://www.r-project.org/.

15. SFOG - Svensk Förening För Obstetrik Och Gynekologi. Robson - ARG, Rapport 2019. 2019. https://www.sfog.se/start/argrupper/robson-arg/rapporter/\%C3\%A5r-2019/ (accessed Aug 31, 2021).

16. WHO - World Health Organization. Tool to calculate caesarean section reference rates at health facilities is launched: the C-Model. Maternal and perinatal health. 2015. https://www.who.int/news/item/29-11-2018-tool-to-calculate-caesarean-section-reference-ratesat-health-facilities-is-launched-the-c-model\#: :text=About\%20the\%20C-

Model\%20A\%20new\%20mathematical\%20model\%20has,of\%20the\%20population\%20that\%20they\%20serve\%20\%28obstetric\%20casemix\%29. (accessed Nov 18, 2021).

17. Souza J, Betran A, Dumont A, et al. A global reference for caesarean section rates (C-Model): a multicountry cross-sectional study. BJOG: An International Journal of Obstetrics \& Gynaecology 2016; 123: 427-36.

18. Chaudhary P, Dar lang M, Mahendra S, Devkota M, Poudel P, Rath AD. Using robson and C-model to understand variability in caesarean section rates in nepal hospitals. International Journal of Gynecology and Obstetrics 2018; 143: 298.

19. Ray A, Thomas BM, Gopi A. Applying the WHO C-Model in a tertiary care hospital to optimise C-Section rates. Journal of Obstetrics and Gynaecology Research 2017; 43: 36-7.

20. Abdel-Aleem H, Darwish A, Abdelaleem AAA, Mansur M. Usefulness of the WHO C-Model to optimize the cesarean delivery rate in a tertiary hospital setting. Int J Gynaecol Obstet 2017; 137: 40-4.

21. Vogel JP, Betrán AP, Vindevoghel N, et al. Use of the Robson classification to assess caesarean section trends in 21 countries: a secondary analysis of two WHO multicountry surveys. The Lancet Global Health 2015; 3: e260-70.

22. Robson M, Hartigan L, Murphy M. Methods of achieving and maintaining an appropriate caesarean section rate. Best Pract Res Clin Obstet Gynaecol 2013; 27: 297-308.

23. Nakamura-Pereira M, Esteves-Pereira AP, Gama SGN, Leal M. Elective repeat cesarean delivery in women eligible for trial of labor in Brazil. International Journal of Gynecology \& Obstetrics 2018; 143: $351-9$.

24. Mendes YMMB e, Rattner D. Cesarean sections in Brazil's teaching hospitals: an analysis using Robson Classification. Rev Panam Salud Publica 2021; 45: 1.

25. Ministério da Saúde (BR), Secretaria de Ciência T e IE, Departamento de Ações Programáticas Estratégicas, Departamento de Gestão e Incorporação de Tecnologias em Saúde, CONITEC - Comissão Nacional de Incorporação de Tecnologias, Secretaria de Atenção à Saúde. Diretrizes de Atenção à Gestante: a operação cesariana. Brasília: CONITEC - Comissão Nacional de Incorporação de Tecnologias no SUS, 2015.

26. Ministério da Saúde (BR), Secretaria de Ciência T e IE, Departamento de Ações Programáticas Estratégicas, Departamento de Gestão e Incorporação de Tecnologias em Saúde, CONITEC - Comissão Nacional de Incorporação de Tecnologias, Secretaria de Atenção à Saúde. Diretrizes Nacionais de Assitência ao Parto Normal. Brasília, 2017 https://bvsms.saude.gov.br/bvs/publicacoes/diretrizes_nacionais_assistencia_parto_normal.pdf (accessed Sept 20, 2021).

27. Rudey EL, Leal M do C, Rego G. Cesarean section rates in Brazil. Medicine 2020; 99: e19880.

28. Rudey ELEL, Leal MDCM do C, Rego G, et al. Cesarean section rates in Brazil: Trend analysis using the Robson classification system. Medicine 2020; 99: e19880.

29. R K, TJP L, MO M, et al. Cesarean-section Rates in Brazil from 2014 to 2016: Cross-sectional Analysis Using the Robson Classification. Rev Bras Ginecol Obstet 2020; 42: 522-8.

30. Torres JA, Domingues RMSM, Sandall J, et al. Cesariana e resultados neonatais em hospitais privados no Brasil: estudo comparativo de dois diferentes modelos de atenção perinatal. Cadernos de Saúde Pública 2014; 30: S220-31.

31. Paixao ES, Bottomley C, Smeeth L, et al. Using the Robson classification to assess caesarean section rates in Brazil: an observational study of more than 24 million births from 2011 to 2017. BMC Pregnancy and Childbirth 2021; 21: 589.

32. Chang Pecci C, Mottl-Santiago J, Culpepper L, Heffner L, McMahan T, Lee-Parritz A. The Birth of a Collaborative Model. Obstetrics and Gynecology Clinics of North America 2012; 39: 323-34.

Page 13/15 
33. Faucher MA, Collins-Fulea C, Breedlove G. Collaboration in Practice: Implementing Team-Based Practice: A Midwifery Perspective. Journal of Midwifery \& Women's Health 2016; 61: 408-10.

34. OMS - Organização Mundial da Saúde. WHO recommendations on intrapartum care for a positive childbirth experience. Geneva: World Health Organization, 2018.

35. Marshall N, Egan S, Flores C, Kirsch A, Mankoff R, Resnick M. Working Toward a Common Goal. Obstetrics and Gynecology Clinics of North America 2012; 39: 373-82.

36. King TL, Laros RK, Parer JT. Interprofessional Collaborative Practice in Obstetrics and Midwifery. Obstetrics and Gynecology Clinics of North America 2012; 39: 411-22.

\section{Figures}

Figura 1 - Classificação por Grupos de Robson

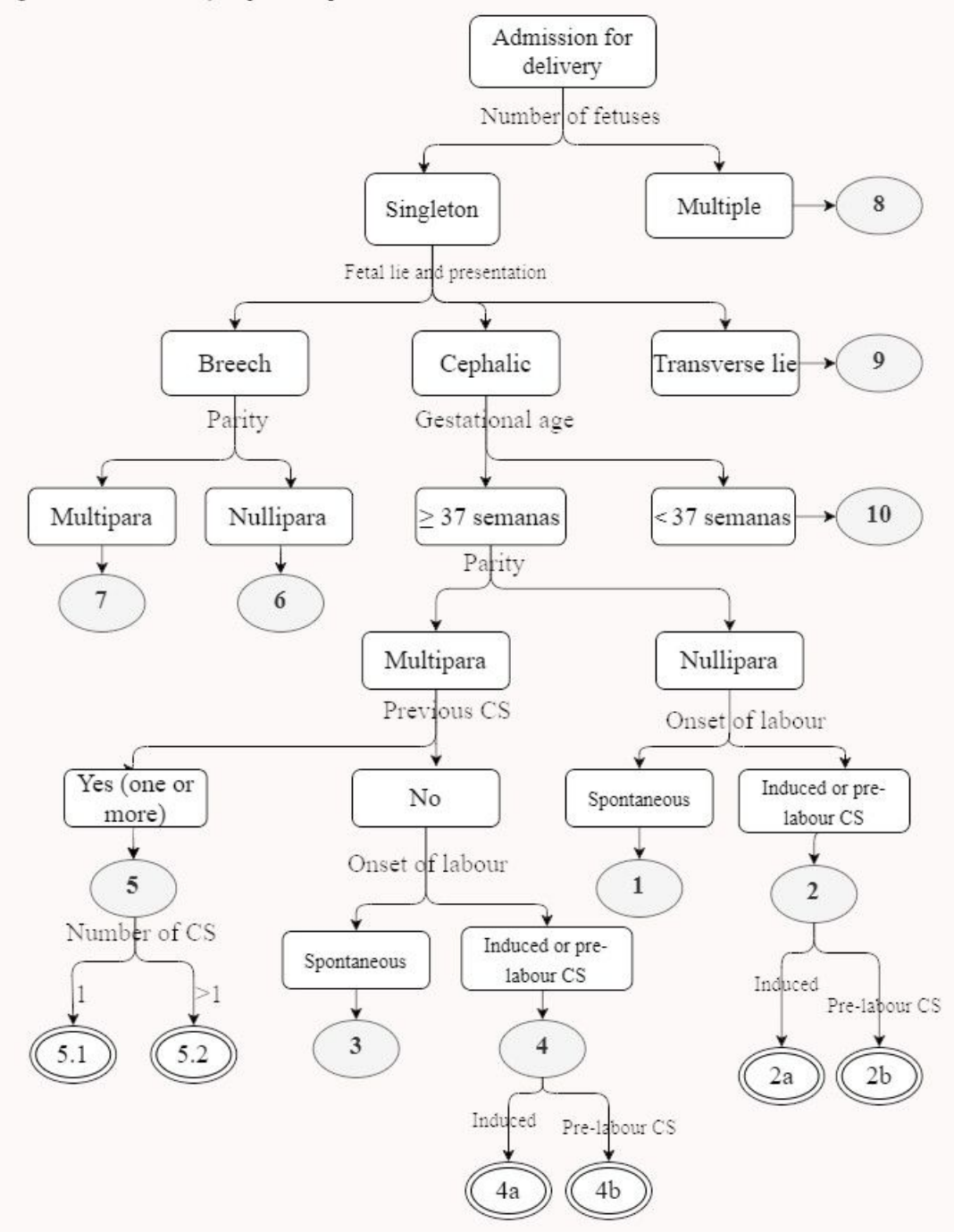

Fonte: Elaboração própria a partir de dados da OMS (2017)

\section{Figure 1}

The Robson Classification with subdivisions. Source: Authors' elaboration based on WHO data (2017)2 

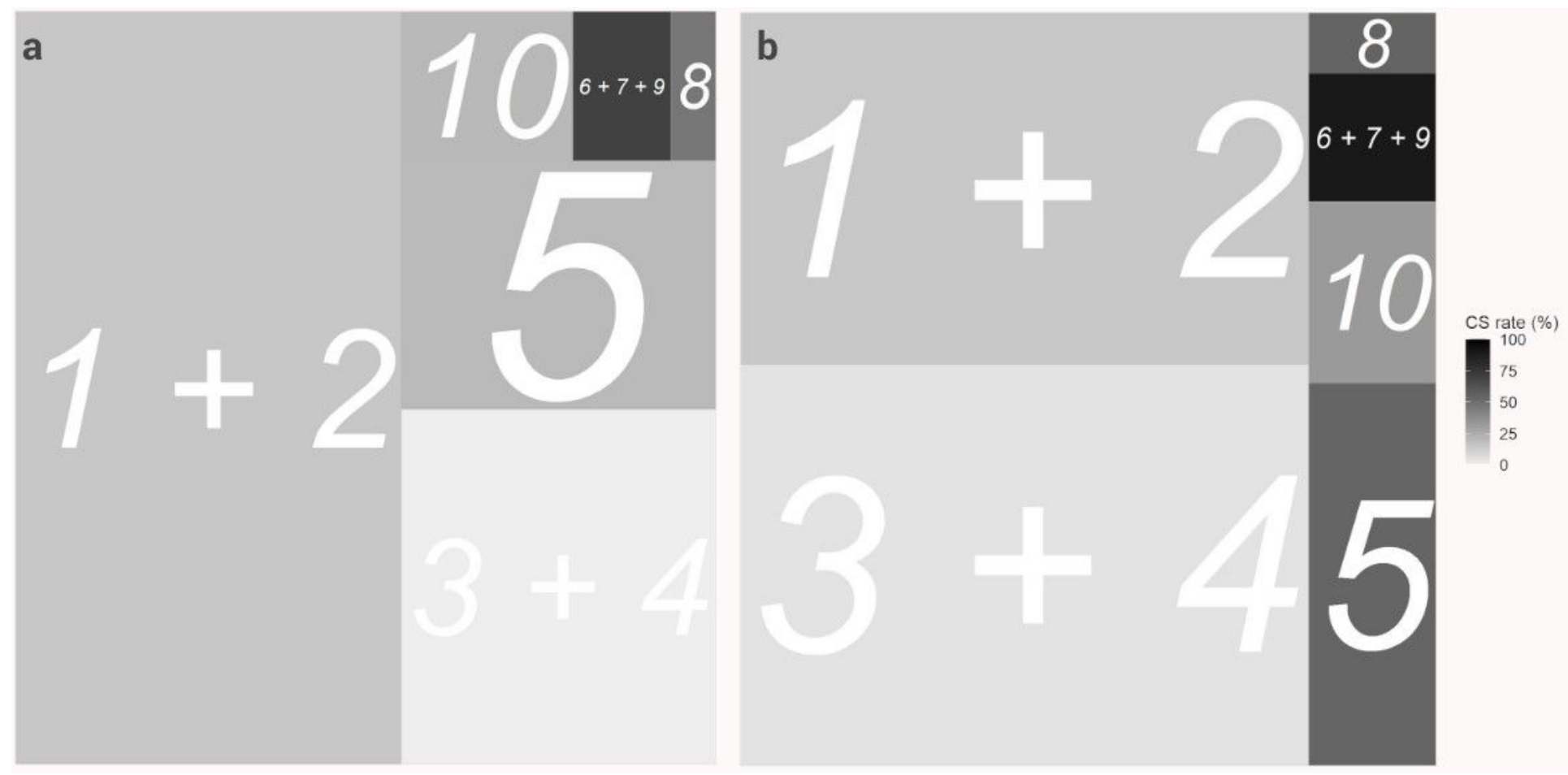

Figure 2

Robson's Groups size and CS rates, grouped by common characteristics, private practice, Brazil (2014 to 2019) (a) and Sweden (2019) (b). Source: PP data and SFOG15 